\title{
The Effect of Dual Strain Probiotic on the Growth and Feeding Intolerance in Premature Neonates of Kabul city: A Randomized Clinical Trial
}

Mansoor Aslamzai ( $\square$ mansooraslamzai@gmail.com )

Kabul University of Medical Science

Abdul Rahim Raheen

Kabul University of Medical science

Mohammad Farouq Hamidi

Kabul University of Medical Science

Zemary Hassin

Kabul University of Medical Science

Research article

Keywords: Newborn, growth, preterm and probiotic

Posted Date: November 17th, 2020

DOl: https://doi.org/10.21203/rs.3.rs-102536/v1

License: (c) (i) This work is licensed under a Creative Commons Attribution 4.0 International License.

Read Full License 


\section{Abstract}

Background: Prematurity is prevalent worldwide and accounts as the leading cause of neonatal death. Slow weight gain, feeding intolerance, prolong hospital stay, recurrent infection and high mortality are significant issues for preterm neonates. Dual strain probiotic can manage such complication of prematurity.

Objective: To evaluate the effectiveness of dual strain probiotic on weight gaining and feeding intolerance of preterm neonates in Kabul city.

Method: This randomized controlled trial conducted at Neonatal units of Malalai and Maiwand Hospitals in Kabul city. Finally, 84 preterm neonates assessed for the effect of dual strain probiotic. The clinical parameters were daily weight gain and the risk of feeding intolerance and neonatal mortality. Statically analysis was performed by SPSS 20.

Results: Forty-two premature neonates in dual strain probiotic group and another forty-two preterm babies in control group were investigated. The preterm neonates in probiotic versus control group had mean age ( $(7.2 \pm 6.3$ vs $6.8 \pm 3.3$ day; $P=0.63)$, weight $(1495.5 \pm 273$ vs $1476.2 \pm 273 \mathrm{~g} ; \mathrm{P}=0.75)$ and gestational age $(33.6 \pm 2.1$ vs $32.9 \pm 2.4$ week; $p=0.14)$. Sex distribution in probiotic group was (boys $54.4 \%$, girl $45.2 \%$ ) and in control group was (boys $50 \%$, girl $50 \%$ ). Both groups were observed for mean days of (17.6 \pm 6.4 vs $18.8 \pm 6.3 ; P=0.45)$. The premature newborns in probiotic versus control group had mean daily weight gain $(15.4 \pm 9.4$ vs $10 \pm 7.9 \mathrm{~g} ; \mathrm{Cl}=1.75-9.31, P=0.005)$, risk of feeding intolerance $(R R=0.65$, $\mathrm{Cl}=0.1-4.1, \mathrm{P}=0.6)$ and risk of mortality during hospital stay $(\mathrm{RR}=0.65, \mathrm{Cl}=0.1-0.41, \mathrm{P}=0.8)$.

Conclusion: Preterm neonates in our country had slow growth than high-income countries. Dual strain probiotic significantly improved the daily weight gain of premature neonates. However, probiotic also decreased the risk of feeding intolerance and death during hospital stay but these findings were not statistically significant.

Clinical trial registration number: This RCT was registered in the Australian New Zealand Clinical Trials Registry with the number of ACTRN12620000538943. Date of Registration is first May 2020. https://www.anzctr.org.au/ACTRN12620000538943.aspx

\section{Introduction}

The neonatal deaths in 2017 estimated 2.4-2.8 million and 99\% of these deaths occurred in low-income and middle income countries. ${ }^{1,2}$ It has been estimated that 15 million preterm babies are born worldwide every year. ${ }^{3}$ The neonatal mortality rate in Afghanistan is one of the highest in the world and it is reported by UNICEF in 2019; 37 deaths per 1000 live births. ${ }^{4,5}$ One of the main causes of neonatal mortality in Afghanistan is preterm birth that accounts $35 \%$ such death. ${ }^{6}$ Apart from high mortality, Prematurity is also an important cause of neuromotor disability. ${ }^{3,7}$ Birth weight is the single most important marker of adverse perinatal and neonatal outcome. Over $80 \%$ of all neonatal death, in both the 
developed and developing countries, occur among the low birth weight babies. ${ }^{7}$ As the maturation of motor activity in premature infants lags behind, therefore, it causes disorder of gastrointestinal motility that limits the use of enteral feeding in this population. An adequate establishment of the intestinal flora after birth is strictly related to motility maturation and plays a crucial role in the development of gut barrier function and the innate and adaptive immune system ${ }^{8}$. Slow growth and feeding intolerance are major issues in premature infants, resulting in prolonged hospitalization and a predisposition to serious complications. A delay in reaching full enteral feedings is also associated with a poorer mental outcome in preterm neonates at 24 months corrected age. ${ }^{9}$

The term probiotics is defined as 'live microorganisms when administered in adequate amounts confer a benefit for the host. ${ }^{3,10}$ The beneficial mechanisms of probiotics are including changes in intestinal permeability, enhanced mucosal IgA responses, increased production of anti-inflammatory cytokines, intestinal maturation and maintain mucosal integrity. The immature immune system of premature neonates cannot control the outgrowth of pathogenic bacteria. ${ }^{10-12}$ Based on multiple beneficial mechanisms of probiotic strains, dual-strain probiotics may be more effective than single-strain probiotics. ${ }^{11} \mathrm{~A}$ few studies assessed the effect of probiotic on the weight gaining of premature neonates but the results are controversial and conflicting. The use of single-strain probiotic containing Lactobacillus acidophilus/ Bifidobacterium infantis or Saccharomyces boulardii, was associated with increased neonatal weight gain per day. ${ }^{12,13}$ Four-strain probiotic showed no significant effect on mean weight gain of preterm neonates. ${ }^{14}$ Full enteral feeds developed earlier among neonates receiving probiotics. ${ }^{15}$ Oral probiotics supplementation significantly reduced the risk of NEC and neonatal mortality. ${ }^{15-17}$ It is also safe, and effective in reducing the risk of late onset sepsis in preterm neonates. $10,15,18$

Effective feeding of preterm and low birth weight neonates can reduce the complication and mortality of prematurity, and weight gaining is an essential aspect of neonatal care. During the first three weeks of life in preterm neonates with birth weight of $1000-2000 \mathrm{gr}$, the mean daily weight gains is $5-20 \mathrm{gr} .{ }^{19}$ On the second week after birth, preterm babies have the slowest mean growth velocity of $6.8 \mathrm{~g} / \mathrm{kg} / \mathrm{day} .{ }^{20}$ Such slow weight gaining is more challenging for the neonatal care in our country because of less advanced neonatal units. Enhancing preterm neonatal growth may decrease complications, hospital stays and mortality, and highly required for the better neonatal care.

At the moment, a little evidences demonstrated the effect of probiotic on the growth of preterm neonates. ${ }^{12,13}$ Moreover, among the many strategies tried for enhancing weight gaining and feeding tolerance of preterm neonates, administration of probiotic is the most promising issue. The current study compared the effectiveness of dual strain probiotic-fortified milk versus probiotic non-fortified milk on the growth and feeding intolerance of preterm neonates in Kabul hospitals.

\section{Research objectives}


To compare the effectiveness of dual strain probiotic fortified breast milk versus non-fortified breast milk on weight gaining and feeding intolerance of preterm neonates with a gestational age of equal or less than 35 week or weight less than $2000 \mathrm{~g}$ in Kabul hospitals.

\section{Research Hypothesis}

Dual strain probiotic fortified breast milk is more effective than non-fortified breast milk for the management of preterm neonates.

\section{Method And Materials}

\section{Study Design and setting}

To be able to fulfill the objective of the proposed study, Prospective Randomized Controlled Trail design was employed at Malalai and Maiwand hospitals in Kabul city during May-October 2020.

\section{Study population}

The study population was comprised of preterm neonates (Infant up to 28 day old) with weight less than $2000 \mathrm{~g}$.

\section{Inclusion and exclusion criteria}

Preterm neonates with gestational age $\leq 36$ weeks or weight less than $2000 \mathrm{~g}$ enrolled in the study. We excluded the neonates with visible or physically detected malformation, birth weight less than $1000 \mathrm{gr}$, severe birth asphyxia, seriously ill baby and parent who declined consent.

\section{Sampling strategy and sample size}

Block randomized sampling was used to recruit the study participants. Stata 14 used for sample size calculation. A hypothesized mean increment of $3 \mathrm{~g}$ in daily weight gain for the probiotic group took in consideration. The preterm and low birth weight neonate grows about $6.8 \pm 4.8 \mathrm{gr} / \mathrm{day}$. With alpha error of $5 \%$ and power of $80 \%$, the two-sample means test estimated a sample size of 84 neonates ( 42 baby for each group). Forty-two premature neonates managed by dual strain probiotic (Probiotic group), and the other forty-two premature neonates took under routine care (Control group).

\section{Material}

Dual strain probiotic, mother breast milk, premature formula, nasogastric tube (NGT) and syringes were used for the feeding of preterm infants. Premature formulas and dual strain probiotic purchased by the research project. Pre Biomil was a premature formula that made by FASSKA in France. Gutcare a dual strain probiotic that each sachet containing $500 \mathrm{mg}$ Bifidobacterium and Clostridium butyricum was a product of Searle, Pakistan. 


\section{Procedure}

Totally 93 preterm neonates were studied for the effectiveness of probiotic on the growth and feeding intolerance. Six patients did not meet the inclusion criteria due to less than $1000 \mathrm{~g}$ weight (3 neonates) and critical ill condition (3 neonates). From 87 patients, 43 preterm newborn babies received mother breast milk or formula feeding together with dual strain probiotic and the other 44 babies took nonprobiotic fortified mother breast-feeding or formula feeding. There were one and two cases of loss to follow up in probiotic and control groups respectively (Figure-1).

In the probiotic group, forty-two neonates were feed by mother breast milk together with dual strain probiotic (Gutcare) half sachet $(250 \mathrm{mg}$ ) dissolved in 1-3 ml milk twice daily. The probiotic-fortified milk started from day 4 and continued for 1-3weeks. In the control group (forty-two), non-probiotic fortified mother breast-feeding was the choice.

The routine management such as incubator care, fluid and electrolyte maintenance, expressed breast milk (EBM) and premature formula via NGT for infants less than $1800 \mathrm{gr}$ or gestational age $\leq 35$ weeks undertook for two mentioned groups. EBM initiated as trophic feeds of 10 to $20 \mathrm{~mL} / \mathrm{kg} /$ day at 2 hourly intervals in hemodynamically stable infants. Feeds advanced by $20 \mathrm{~mL} / \mathrm{kg} /$ day up to $150 \mathrm{ml} / \mathrm{kg} /$ day

Primary outcome measures were daily weight gain and feeding intolerance defined $\geq$ two episode of vomiting during last $6 \mathrm{hr}$. Secondary outcome measures is neonatal death during hospital stay.

\section{Variables}

Main variables were

- Daily weight gain was calculated as weight gain in gram during observation period divided by number of days.

- Risk of feeding intolerance defined as $\geq$ two episodes of vomiting during last $6 \mathrm{hr}$.

- Gestational age as weeks, determined by LMP or antenatal maternal ultrasound or gestational age assessment by neonatal heel-toe distance.

- Risk of neonatal death during hospital stay.

\section{Data collection tools \& Statistical analysis}

Initially raw data were collected in data collection sheets and then entered in SPSS software for statistical analysis. The evaluation of efficacy performed by comparing the mean and RR with the consideration of $\mathrm{p}$-value. To detect the significance level, the mean of normally and non-normally distributed data were compared by independent t-test and Mann-Whitney test, respectively. Chi-square test was performed for dichotomous data. As we accepted the alpha errors of 0.05 , therefore, the $p$-value $<0.05$ was significant.

\section{Ethical consideration}


The proposal of this RCT was registered in the Australian New Zealand Clinical Trials Registry (ANZCTR) with the registration number of ACTRN12620000538943. The department of Neonatology, Kabul University of Medical Science (KUMS) and Research committee of Ministry of Higher Education of Afghanistan approved the RCT proposal and final report on the basis of Helsinki Declaration. The consents of parent were taken.

\section{Results}

Finally, eighty-four preterm newborn babies were studied for the effectiveness of dual strain probiotic on the growth and feeding intolerance in Neonatal units of Malalai and Maiwand hospitals of Kabul city, Afghanistan. Forty-two premature neonates received dual strain probiotic along with breast or formula feeding and another forty-two preterm babies were feed by mother breast milk or formula feeding. The baseline characteristics of neonates are shown in [Table-1].

As shown in [Table-1], neonates in probiotic and control groups have similar mean age, weight, gestational age and observation days but these finding are not statistically significant. The distribution of weight and gestational age classes, sex and mode of delivery are approximately similar in both groups with non-significant $\mathrm{p}$-value.

After the intervention, we determined the mean daily weight gain, risk of feeding intolerance and mortality during hospital stay [Table-2].

Table-2 describes, mean daily weight gain are significantly higher in neonates managed by probiotic. However, the risk of feeding intolerance and mortality are higher in control group but such findings are not statistically significant.

\section{Discussion}

The current randomized clinical trial compared the effectiveness of dual strain probiotic fortified milk versus non-probiotic fortified milk on the growth and feeding intolerance of preterm neonates with gestational age less than 37 weeks and weight of 1000-2000 $\mathrm{g}$ in the Neonatal units of Malalai and Maiwand hospitals of Kabul city. Based on the result, dual strain probiotic significantly enhanced the daily weight gaining of preterm neonates [Table-2]. Since probiotics improves enteral nutrition via intestinal maturation and maintain mucosal integrity, ${ }^{10}$ hence it can fasten the weight gain of preterm neonates. As weight is the most important marker of neonatal growth, therefore, the positive effect of probiotic on the weight gaining generate the hypothesis that it may also play a positive role on the other aspect of growth such as height, head circumference and vital organs development. Two RCTs performed by Hartel et al and Xu et al in Germany and China, respectively. ${ }^{12,13}$ Both researches observed significant improvement of weight gain in preterm neonates due to the administration of single strain probiotic. Though all three studies concluded the same effect of probiotic on weight gaining in preterm babies but the mean difference of daily weight gain is higher in the current research, may be related to dual strain 
probiotic. In the study of Hartel, the daily weight gain of premature infants in probiotic and control groups are higher than the index RCT. It shows, in our lower-income society, preterm newborn grows slower than higher-income societies. No significant effect of multistrain probiotic was observed on the growth of preterm neonates in the study of Amini et al. ${ }^{14}$ The mentioned study assessed the effect of multistrain (more than two strain) on the preterm neonate weighing 750-1500 $\mathrm{g}$ and had gestational age of less than 32 weeks. Compared to index RCT; type of probiotic and weight and gestational age of patients are different. Mohan et al conducted a clinical randomized trial at the Ernst von Bergmann hospital in Potsdam, Germany. The result demonstrated, single probiotic (Bifidobacterium lactis Bb12) had no effect on weight. ${ }^{15}$ This difference may be attributed to the distinct probiotic strain and small sample size of second study. However, risk of feeding intolerance and death were declined by dual strain probiotic but these findings were not statistically significant. The prophylactic effect of dual-strain probiotics in preterm neonates was assessed by Denkel et al in Germany. The result showed, dual-strain probiotics significantly reduced the risk of overall neonatal mortality, NEC and nosocomial infection. ${ }^{17}$ Singh et al conducted a retrospective cohort study to examine the efficacy of probiotic on preterm neonates in Canada. The NEC and mortality were significantly lower in the probiotic group. ${ }^{21}$ The last two studies assessed very and extremely low birth neonates for a long time. As we excluded preterm neonates with seriously ill condition and weight less than $1000 \mathrm{~g}$, therefore, such difference may be observed.

\section{Limitation}

Though majority of patients were managed for three weeks but the minimum period of observation was one week in rare cases, therefore, we recommend further investigation for the efficacy of dual strain probiotic administrated at least for three weeks.

\section{Conclusion}

The current study demonstrated, the growth of preterm neonates in our country was slower than the higher-income countries. Dual strain probiotic significantly increased the daily weight gain of premature infants weighing less than $2000 \mathrm{~g}$. However, risk of feeding intolerance and death were declined by dual strain probiotic but these findings were not statistically significant.

\section{Declarations}

\section{Ethics approval and consent to participate}

The proposal of this RCT was registered in the Australian New Zealand Clinical Trials Registry (ANZCTR) with the registration number of ACTRN12620000538943. The department of Neonatology, Kabul University of Medical Science (KUMS) and Research committee of Ministry of Higher Education of Afghanistan approved the RCT proposal and final report on the basis of Helsinki Declaration. The consents of parent were taken. 


\section{Consent for publication}

Not applicable.

\section{Availability of data and materials}

The datasets used and/or analyzed during the current study are available from the corresponding author on reasonable request.

\section{Competing interests}

The authors declare they have no interest of conflict.

\section{Funding}

The Ministry of Higher Education of Afghanistan and World Bank prepared the facilities for this RCT.

\section{Authors' contribution}

Conceptualization, design, data analysis, manuscript drafting, editing and reviewing was performed by first author. The second author revised the manuscript, third and fourth authors designed the data collection instruments, and coordinated and supervised data collection. The final report was approved by all authors.

\section{Acknowledgement}

We gratefully acknowledge the Ministry of Higher Education of Afghanistan, Higher Education Development Program (HEDP) and the World Bank for preparing the facilities; we also thank the staff of Neonatal ward of Malalai hospital, especially Doctor Atiqulla Halimi for the cooperation to this study.

\section{References}

1. Hug L, Alexander M, You D, Alkema L. National, regional, and global levels and trends in neonatal mortality between 1990 and 2017, with scenario-based projections to 2030: A systematic analysis. The Lancet Global Health 2019;7(6): e710-20.

2. Hug L, Sharrow D, You D. Levels and Trends in Child Mortality. UNICEF 2017. Available from: https://www.unicef.org/publications/index_103264.html

3. Greenberg, JM. Overview of Morbidity and Mortality. In: Kliegman, RM. St Jeme, JW.Blum, NJ. et al NELSON TEXTBOOK OF PEDIATRICS. $21^{\text {st }}$ Philadelphia. Elsevier. 2020; Ch. 112. ISBN:978-0-32352950-1.

4. UNICEF, Neonatal mortality. UNICEF DATA 2018. Available from: https://data.unicef.org/topic/childsurvival/neonatal-mortality/

5. Health, Afghanistan 2019. Available from: https://www.unicef.org/afghanistan/health 
6. Ansari N. The causes of neonatal mortality in Afghanistan. $48^{\text {th }}$ International course in health development 2012. Available from: http://www.bibalex.org/Search4Dev/files/428883/455711.

7. Sing, M. Preterm baby. In Care of the Newborn. 8th ed. New Delhi. CBD 2015. Ch.17, PP.299-321.

8. Indrio F, Riezzo G, Cavallo L, Mauro AD, Francavilla R. Physiological basis of food intolerance in VLBW. J Matern Neonatal Med 2011; 24:64-6.

9. Morris BH, Miller-Loncar CL, Landry SH, Smith KE, Swank PR, Denson SE. Feeding, medical factors, and developmental outcome in premature infants. Clinical Pediatric 1999; 38:451-7.

10. Zhang L, Li N and Neu J. Probiotic for preterm infants. Immunology 2009; (6)5: e227-232. DOI: 10.1542/neo.6-5-e227.

11. Deshpande GC, Rao SC, Keil AD et al. Evidence-based guidelines for use of probiotics in preterm neonates. BMC Med 9, 92 (2011) doi:10.1186/1741-7015-9-92.

12. Hartel C, Page J, Rupp J, Bendiks M,Guthmann F,Rieger-Fackeldey E, Heckmann M, Franz A et al. Prophylactic use of Lactobacillus acidophilus/ Bifidobacterium infantis probiotics and outcome in very LBW infants. The Journal of Pediatrics. 2014; 165:285-9. http://dx.doi.org/10.1016/j.jpeds.2014.04.029.

13. Xua $L$, Wang $Y$, Wang $Y$, Fua J, Sun $M$, Zhiqin Mao Z, et al. A double-blinded randomized trial on growth and feeding tolerance with Saccharomyces boulardii CNCM I-745 in formula-fed preterm infant. Jornal de Pediatria 2016;92(3). https://doi.org/10.1016/j.jped.2015.08.013.

14. Amini E, Dalili H, Niknafs N, Shariat M, Nakhostin M, Jedari-Attari S. The Effect of Probiotics in Prevention of Necrotising Enterocolitis in Preterm Neonates in Comparison with Control Group. IRANIAN JOURNAL OF PEDIATRICS 2017;27(6); e7663. DOI: 10.5812/ijp.7663

15. Mohan R, Koebnick C, Schildt J,Mueller M, Radke M, Blaut M. Effects of Bifidobacterium lactis Bb12 Supplementation on Body Weight, Fecal pH, Acetate, Lactate, Calprotectin, and IgA in Preterm Infants. Pediatrics Research. 2008;64, 418-422. doi:10.1203/PDR.0b013e318181b7fa.

16. Lau, CSM. Chamberlain, RS. Probiotic administration can prevent necrotizing enterocolitis in preterm infants: A meta-analysis. Journal of Pediatric Surgery 2015; (50) 8:1405-1412. https://doi.org/10.1016/j.jpedsurg.2015.05.008.

17. Denkel LA, Schwab F, Garten L, Geffers C, Gastmeier P, Piening B. Protective effect of Daul-Strain Probiotics in Preterm infants. A MultiCentre Time Series Analysis. PLos ONE. 2016; 11(6): e0158136. DOI: 10.1371/journal.pone.0158136

18. Alfaleh, KM. Bassler, D. Probiotic for prevention of necrotizing enterocolitis in preterm infants. The Cochrane Collaboration. John Wiley \& Sons, 2009; Issue 1. http://www.thecochranelibrary.com.

19. Anchieta, L.M. Xavier, C.C. Colosimo, E.A. and Souza, M.F. Weight of preterm newborns during the first twelve weeks of life. Brazilian Journal of Medical and Biological Research 2003. 36: 761-770.

20. Mlay IE, Mchaile DN, Shayo AM. Growth Velocity and Factors Associated with Poor Postnatal Growth Rate Among Preterm Infants at KCMC: A Prospective Cohort Study. Research and Reports in Neonatology. 2020; 10:59-66. https://doi.org/10.2147/RRN.S256628 
21. Gómez-Rodríguez, G. Amador-Licona, N. Daza-Benítez L. et al. Single strain versus multispecies probiotic on necrotizing enterocolitis and faecal IgA levels in very low birth weight preterm neonates: A randomized clinical trial. Pediatrics and Neonatology. 2019;60(5):564-569. DOI: https://doi.org/10.1016/j.pedneo.2019.02.005.

\section{Tables}

Table-1: Baseline characteristics of neonates 


\begin{tabular}{|c|c|c|c|}
\hline Characteristics & $\begin{array}{l}\text { Probiotic group } \\
\text { (42 neonates) }\end{array}$ & $\begin{array}{l}\text { Control group } \\
\text { (42 neonates) }\end{array}$ & P-value \\
\hline Age in days, Mean (SD) & $7.19(3.63)$ & $6.83(3.31)$ & 0.63 \\
\hline $\begin{array}{l}\text { Weight in gram } \\
\text { Mean (SD) }\end{array}$ & $1495.48(273.21)$ & $1476.19(273.49)$ & 0.74 \\
\hline $\begin{array}{l}\text { Gestational age in week } \\
\text { Mean (SD) }\end{array}$ & $33.64(2.10)$ & $32.98(2.41)$ & 0.14 \\
\hline \multicolumn{4}{|l|}{ Class of Weight, No (\%) } \\
\hline $1500-2000 \mathrm{~g}$ & $22(52.4)$ & $26(61.9)$ & 0.25 \\
\hline $1000-1499 \mathrm{~g}$ & $20(47.6)$ & $16(38.1)$ & \\
\hline \multicolumn{4}{|l|}{ Class of GA, No (\%) } \\
\hline Late Preterm (35-36 W) & $17(40.5)$ & 13(31.0) & 0.63 \\
\hline Moderate Preterm (32-34 W) & $19(42.2)$ & $21(50.0)$ & \\
\hline Early Preterm (<32W) & $6(16.66)$ & $8(19.0)$ & \\
\hline \multicolumn{4}{|l|}{ Sex, No (\%) } \\
\hline Boy & $23(54.8)$ & $21(50)$ & 0.82 \\
\hline Girl & $19(45.2)$ & $21(50)$ & \\
\hline \multicolumn{4}{|l|}{ Mode of Delivery, No (\%) } \\
\hline Vaginal & $34(81.0)$ & $30(71.4)$ & 0.44 \\
\hline Cesarean & $8(19.0)$ & $12(28.6)$ & \\
\hline $\begin{array}{l}\text { Observation days } \\
\text { Mean (SD) }\end{array}$ & $17.64(6.41)$ & $18.69(6.30)$ & 0.45 \\
\hline
\end{tabular}

$\mathrm{SD}=$ Standard deviation, $\mathrm{GA}=$ Gestational age, $\mathrm{g}=$ gram, $\mathrm{W}=$ Week

Table-2: The efficacy of probiotic in preterm neonates. 


\begin{tabular}{|lllll|}
\hline Findings & $\begin{array}{l}\text { Probiotic group } \\
\text { (42 neonates) }\end{array}$ & $\begin{array}{l}\text { Control group } \\
\text { (42 neonates) }\end{array}$ & 95\% Cl & P-value \\
\hline $\begin{array}{l}\text { Daily weight gains in gram } \\
\text { Mean (SD) }\end{array}$ & $15.54(9.41)$ & $10.01(7.93)$ & $1.75-9.31$ & 0.005 \\
\hline $\begin{array}{l}\text { Feeding in tolerance, No (\%) } \\
\text { RR (Risk Ratio) }\end{array}$ & $2(4.8)$ & $3(7.1)$ & $0.10-4.10$ & 0.64 \\
\hline $\begin{array}{l}\text { Mortality, No. (\%) } \\
\text { RR (Risk Ratio) }\end{array}$ & 0.65 & 1.5 & & \\
\hline
\end{tabular}

\section{Figures}

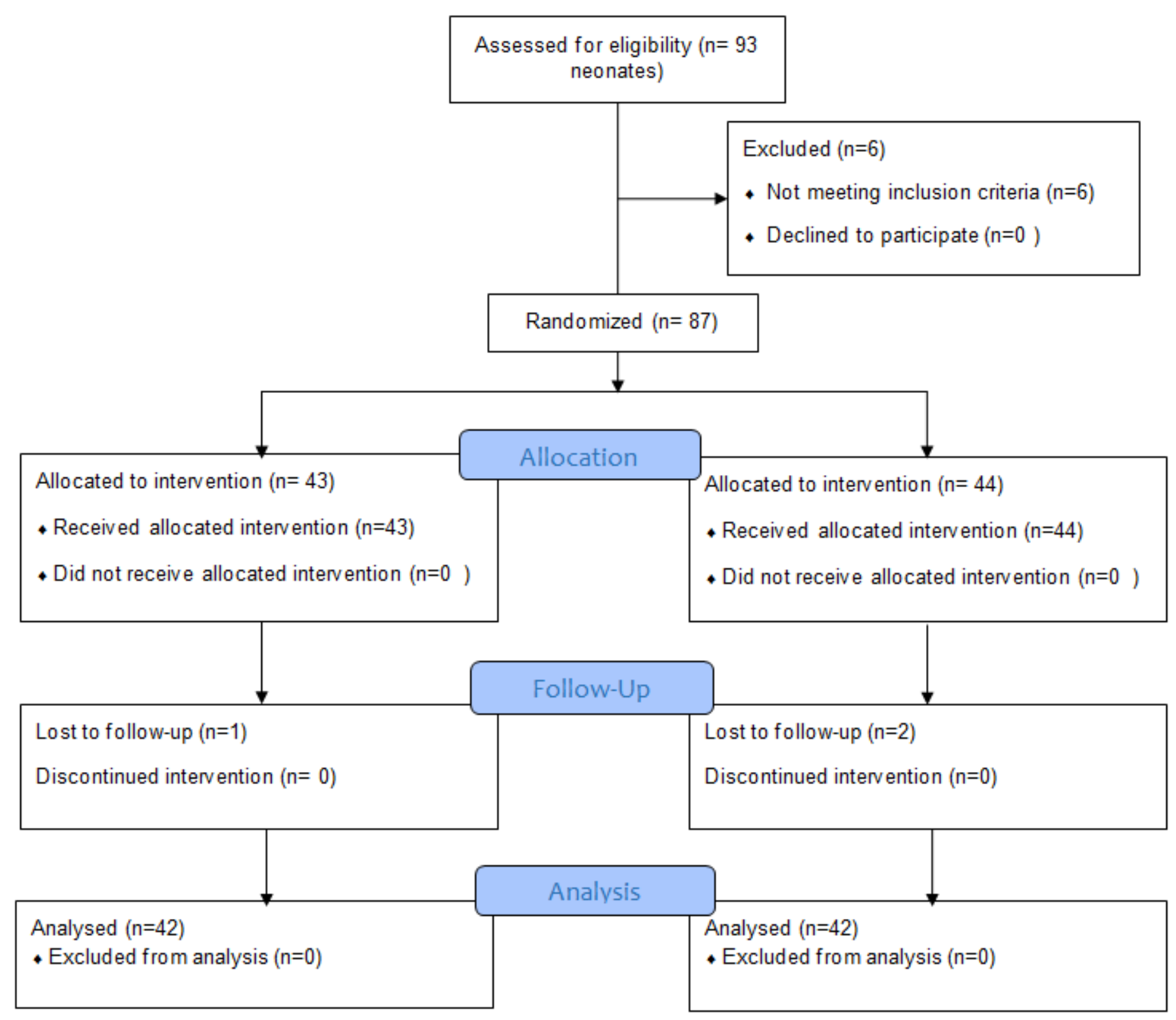




\section{Figure 1}

Flow diagram for the patient distribution 